\title{
Nascimento de um produto turístico: caracterização de um atrativo rural na Terra dos Pinheirais (PR)
}

\author{
Formatting a tourist product: the rural attractive \\ characterization at Terra dos Pinheirais (PR, Brazil)
}

\author{
Leandro Baptista, Elieti Fátima de Goveia
}

RESUMO: O processo de modernização da agricultura ao mesmo tempo em que proporcionou um aumento na produção, garantindo o alimento necessário para as populações, provocou uma queda na necessidade de mão de obra no campo, desarticulando assim formas tradicionais de produção. Enquanto parte desta população migrou para as cidades, outros necessitaram buscar novas fontes de renda, ampliando sua produção de matéria prima para outros setores com características não-agrícolas. Paralelamente a este processo, o meio rural deixou de ser visto apenas como um espaço para a produção agrícola e passou a ser considerado também como um local de lazer, moradia, descanso, dentre outras funções. Entre este amálgama de novas atividades desenvolvidas no meio rural, surgiu o turismo, como uma atividade capaz de gerar renda e a estimular as pessoas a continuarem na zona rural. Diante deste contexto, a localidade do Pinho de Baixo, interior de Irati (PR), reconhecida por suas vinícolas, seu museu que retrata a colonização do município por italianos (Casa Dei Nonni) e a tradicional festa da polenta, iniciou atividades correlatas ao turismo a partir de abril de 2016, objetivando diversificar a oferta de produtos fundamentado pela base comunitária. Além destas características, encontra-se no Pinho de Baixo recursos turísticos naturais como cachoeira, paisagens preservadas e o local também recebe uma das etapas do evento "Cicloturismo Irati", consolidado no calendário municipal. Assim, com o intuito de verificar a potencialidade do produto turístico, objetiva-se nesta investigação caracterizar os elementos que compõem este novo atrativo, por meio da análise da sinalização turística do local, inventariação das atividades realizadas e análise qualitativa da atual oferta disponível. A metodologia adotada apoiou-se em levantamento de dados primários, obtidos a partir da observação participativa e não-participativa in loco, durante o mês de julho de 2016 e posterior submissão destas informações na matriz de avaliação SWOT.Os resultados sugerem a necessidade de um engajamento maior da comunidade local, a ampliação da oferta, bem como de sua melhora qualitativa, instalação de placas de orientação, restrição e educação, além da promoção da imagem do produto. Como prática de planejamento, são avaliadas estratégias para 0 alcance dos resultados encontrados, caracterizando deste estudo como uma pesquisa aplicada com viés sobre a sustentabilidade ambiental, econômica, social e cultural.

PALAVRAS-CHAVE: Turismo Rural; Base Comunitária; Planejamento; Pinho de Baixo; Irati - PR. 


\section{ABSTRACT}

The modernization process of agriculture at the same time provided an increase to production rates, ensuring the necessary food for the population and caused a decrease in the need for labor in the field, thus disrupting traditional forms of production. As consequence, part of this population migrated to the cities, others needed to seek new sources of income, increasing its production of raw materials for activities with non-agricultural characteristics. Parallel to this process, the countryside become no longer seen only as a space for agricultural production and it has to be considered also as a place of recreation, housing, rest, and other new functions. Among this amalgam of new activities in rural areas, the tourism has emerged as an activity capable of generating income and encourage people to remain in the countryside. Once given this context, the place Pinho de Baixo, inside Irati (PR, Brazil), that has wineries, museum that depicts the colonization of the italians at the city (called Casa Dei Nonni) and the traditional feast of cooked corn meal, had started activities related to tourism from april 2016, aiming to diversify the supply of products based by community-based. Besides these features, is in the Pinho de Baixo some natural tourism resources as waterfall, preserved landscapes and the site also receives one of the stages of the event "Cicloturismolrati", also consolidated in the municipal events calendar. Thus, in order to verify the potential of the tourism product, the paper objective is to characterize this investigation the elements of this new attractive, through the analysis of the tourist site signage, inventory of activities and qualitative analysis of the current offer available. The methodology was relied on primary data collection, obtained from semi-structured by participant observation and non-participatory observation in loco during the month of July 2016 and by application of SWOT method for measuring the data. The results suggest the need a greater involvement of the local community, the expansion of supply, as well as its qualitative improvement, installation of signposts with orientation, restriction and education messages, and the addition to the product image promotion. As a practical planning, strategies are evaluated for the achievement of the results, characterizing this study as an applied research with bias on environmental, economic, social and cultural sustainability.

KEYWORDS: Rural Tourism; Comunity Based; Planning; Pinho de Baixo; Irati PR.

\section{Contextualização inicial}

A questão da globalização, tecnologias de alto custo, fez com que o rural no Brasil transformasse os locais, ou seja, as pequenas propriedades em diferentes formas de alternativa para uma nova opção de empreendimentos da atividade do Turismo Rural no Brasil.

No Paraná, as discussões sobre o turismo rural, assim como as publicações que fundamentam esta nova segmentação e suas políticas, são recentes. Em alguns livros encontram-se apenas algumas linhas que argumentam sobre este segmento no estado, sobre atividade do turismo rural, nas pequenas propriedades, médias e grandes propriedades. Assim, para obter informações com foco no assunto sobre o turismo no Paraná, deve-se recorrer às informações sobre o processo e políticas referentes ao turismo rural, a partir de sites do Ministério de Turismo, Ministério do Desenvolvimento Agrário, SEBRAE, afirmando que o Turismo no Paraná é muito recente. Neste contexto, Almeida e Froehlich (2001) corrobora que a 
atividade do turismo rural, no Paraná praticamente não existia, ou seja, somente na região de Guarapuava havia existência de apenas duas ou três propriedades que desenvolvia tal atividade.

No município de Irati há atualmente a prática de duas atividades com foco no turismo rural: uma na comunidade do Pinho de Baixo, objeto de estudo deste artigo e a segunda, de acordo com Cezário (2014), a propriedade Recanto Daneliv, que está situada na comunidade do Cerro da Ponte Alta; que fica aproximadamente a $28 \mathrm{~km}$ do centro da cidade de Irati/PR, a qual adaptou trabalhos voltados para o segmento de turismo no meio rural a partir de 2013.

Neste contexto, esta pesquisa tem como princípio e importância a realização do estudo sobre as atividades do turismo em uma comunidade, onde preserva a cultura Italiana. Assegurando a este ponto, os pesquisadores trazem como análise à caracterização sobre o nascimento de um novo atrativo no Paraná. Para responder esta questão, foram dimensionados alguns objetivos quanto à questão da investigação, caracterizar os elementos que compõem este novo atrativo, por meio da análise da sinalização turística do local, inventariação das atividades realizadas e análise qualitativa da atual oferta disponível, na comunidade do Pinho de Baixo, a qual deu início às atividades do turismo rural no mês de março de 2016.

A comunidade do Pinho de Baixo, está localizada na área rural do município de Irati, compreende a uma distância de $16 \mathrm{~km}$ do centro da cidade de Irati ao local. A população residente da comunidade, são de etnia Italiana, procuram preservar e manter a cultura de seus antecedentes, através da música, arte, gastronomia, festas, religiosidade, produção agrícola, vinícolas e como também a introdução das atividades para 0 turismo rural na comunidade, tendo como objetivo preservar a cultura de seu povo.

Para o desenvolvimento da metodologia, se baseou na pesquisa qualitativa, descritiva, utilizou-se de dados primários referente à pesquisa de campo na forma de visita técnica, de observação, fotografias, conversa informal com o idealizador das atividades na comunidade do Pinho de Baixo, durante o mês de julho de 2016 e posterior submissão destas informações na matriz de avaliação SWOT. Na sequência deste artigo, foram necessárias algumas abordagens e discussão teórica, para melhor compreender a pesquisa, assim como o fechamento da discussão sobre o objeto de estudo do referido artigo.

Com relação aos resultados, sugere-se a necessidade de um engajamento maior da comunidade local, a ampliação da oferta, bem como de sua melhora qualitativa, instalação de placas de orientação, restrição e educação, além da promoção da imagem do produto. 


\section{Planejamento turístico em áreas rurais}

O planejamento é considerado uma ferramenta essencial para a gestão e o desenvolvimento, capaz de legitimar as decisões num processo consciente e ordenado, necessário para alcançar a sustentabilidade da atividade, pois, o mesmo turismo que gera riquezas, pode acentuar desigualdades sociais e trazer malefícios como a especulação imobiliária, a prostituição, o subemprego e a degradação do meio ambiente, entre outros. Portanto, não há construir um novo produto meramente com a vontade empreendedora, mas necessita-se adequar à realidade que este se insere, visando complementar a oferta de uma região.

Em termos conceituais, Petrocchi (1998, p.20), define planejamento como uma,

(...) visão do futuro próximo ou distante, contribui para que as tarefas sejam melhor realizadas e objetivos sejam mais facilmente atingidos, por pessoas ou organizações. Ordena as ações e da prioridade a elas. Permite mapear dificuldades ou obstáculos e, assim, escolher previamente caminhos alternativos.

Portanto, identifica-se que planejar relaciona-se com a previsão de uma situação futura, portanto, não cabe aos gestores do turismo realizarem predições, mas sim, apoiarem suas decisões e objetivos com um respaldo técnico e logicamente ordenado para o alcance de objetivos-fins. Sob este aspecto, corrobora-se com Bromley (1982 apud DIAS, 2003) ao determinar que as transformações que ocorrem por meio de ações antrópicas não sejam determinadas por circunstâncias fortuitas, mas como resultado de decisões e propósitos pré-determinados.

Por se tratar de uma ferramenta flexível, o planejamento caracterizase assim como um processo dinâmico, onde se permitem revisões e correções, que podem alterar objetivos, readequá-los ou alterar as estratégias para alcançá-los, uma vez que novas premissas na esfera jurídica, social, ambiental, cultural e econômica podem ter reflexos imediatos na consolidação de empreendimentos no setor (BENI, 2004).

Estes reflexos podem ser traduzidos como potenciais impactos que,

Pode ocasionar conflitos sociais, degradação da natureza, desorganização do setor empresarial, perda da demanda, prejudicando o clico de vida do destino. Esta problemática deve-se ao fato de que, quando não controlado, o turismo torna-se uma atividade invasora que pode deteriorar os recursos culturais e naturais de um destino (DREHER, 2003, p. 241).

Portanto, pode-se afirmar que o processo de planejamento assume um caráter fundamental para o desenvolvimento sustentável de uma região, destino ou atrativo isolado. Matrizes de diferentes autores (BENI, 2004; BARRETTO; TAMANINI, 2002; DIAS, 2003) possuem pontos em comum 
para a efetiva realização desta prática, iniciada pela fase de inventário turístico. Neste momento, são registrados o conjunto dos recursos que podem se tornar atrativos, bem como os equipamentos e serviços que podem ou de certa forma já fazem parte da infraestrutura que suportarão a visitação.

Em uma visão mais analítica sobre esta fase, explana-se a mesma como um processo sistemático onde são registrados o conjunto de atrativos, equipamentos e serviços turísticos com objetivo de ordená-los e posteriormente utilizá-los o processo de captação de fluxos de visitantes (BRASIL, 2004).

A compreensão e o reconhecimento da real oferta de uma localidade são indispensáveis no planejamento do turismo. Contudo, este processo vai além de uma lista de itens, fazendo-se necessário classificá-los e avaliá-los de maneira imparcial, considerando assim sua efetiva garantia de atender os desejos do público-alvo. A partir da documentação do inventário, pode-se desenvolver um diagnóstico preciso da situação encontrada.

A fase subsequente do planejamento consiste no diagnóstico de situação, onde os itens inventariados são submetidos a análises quanto seus diferencias, vantagens competitivas, necessidades de adaptação, bem como das carências observadas para a efetiva constituição de um produto de qualidade. Para Dias (2003, p. 97), este momento serve para seja realizada:

(...) a análise do que será planejado procurando identificar as alternativas possíveis, formulando hipóteses e propondo diferentes modelos de desenvolvimento. Após a identificação das alternativas que mais se ajustam as necessidades presentes e futuras, escolhe-se o modelo mais desejável para o desenvolvimento.

Podem ser exemplificados os resultados desta etapa como a compreensão de forma holística da oferta, qual demanda será efetivamente segmentada para o mercado, formulação de projetos futuros, índice de qualidade de recursos humanos, adequação à legislação em seus diferentes níveis governamentais, entre outros. Portanto, entende-se que um diagnóstico deve refletir a realidade local para que seus efeitos sejam mais eficazes no processo de planejamento.

Quanto à operacionalização do diagnóstico, apóia em Mielke e Nascimento (2009, p. 2) quanto determinam que este:

debe indicar estrategias de desarrollo turístico particular y específica para la zona encuestión, definida a partir de una serie de líneas o directrices estratégicas, en base a lascuales si puedeestructurar todo el esquema operativo de laplanificación: ladefinición de objetivos a lograr, laprogramación de acciones y actividades orientada a laconsecución de dichos objetivos, ladefinición de recursos, etc. Pero aún más importante de determinar dichos retos, 
hay que sistematízalos bajo la mirada la congruência de expertos, no solamente de origen endógena, pero también exógena.

Portanto, considera-se a etapa de diagnóstico àquela onde maiores percentuais de tempo e reflexões são necessárias. Pois, se no momento de inventário o trabalho documental prevê o reconhecimento situacional, o diagnóstico por sua vez irá filtrar as informações coletadas, e com parâmetros qualitativos, analisá-las.

Para efeitos deste trabalho, foi utilizado como matriz de avaliação do caso estudado a matriz SWOT, que se refere ao conjunto de elementos internos, representados pelos conceitos de Forças (Strengths) e Fraquezas (Weaknesses), ou seja, aquelas características que podem ser consideradas como pontos positivos e negativos do produto e que têm sua expectativa de gestão por ações diretas da comunidade, bem como do ambiente externo, onde as Oportunidades (Opportunities) e Ameaças (Threats) estão presentes, contudo, só podem ser geridas de forma indireta, por não pertencerem ao domínio do local (MOTA, 2006).

A última etapa deste processo é conceituada como o prognóstico, onde são projetados cenários futuros de situações endossadas pelas informações e projetos alicerçados. Nesta fase, convenciona-se também alinhar o projeto com tendências de mercado, sejam de crescimento, desenvolvimento tecnológico ou posicionamento de mercado, buscando garantir à sustentabilidade do produto planejado. Após a conclusão das etapas anteriores, o local deve estar preparado para a implementação dos trabalhos práticos, onde maiores investimentos são empregados.

Convêm explanar que esta etapa não será desenvolvida neste estudo, uma vez que o objetivo delimitado se refere à caracterização e compreensão da disposição de um novo produto turístico na região rural de Irati - PR, com a perspectiva de diversificação da atual oferta do município e região.

\section{Turismo de base comunitária}

O processo de modernização da agricultura ao mesmo tempo em que proporcionou um aumento de produção, garantindo o alimento necessário para as populações, provocou uma queda na necessidade de mão de obra no campo, desarticulando assim formas tradicionais de produção. Parte desta população migrou para as cidades, caracterizando assim o "êxodo rural", enquanto outros necessitaram buscar novas fontes de renda, ampliando sua produção de matéria-prima para outros setores mesmo com características não-agrícolas.

Paralelamente a este processo, o meio rural deixou de ser visto apenas como um espaço para a produção agrícola e passou a ser considerado também como um espaço de lazer, moradia, descanso, dentre outras funções. Entre este amálgama de novas atividades desenvolvidas no 
meio rural, surge o turismo. Vê-se nele uma possibilidade de gerar renda, estimular as pessoas a continuarem na zona rural e no campo.

No Brasil, o início do Turismo Rural deu-se com as atividades desenvolvidas em Lages em Santa Catarina, na década de 80, quando após a crise dos anos 70, produtores rurais decidiram desenvolver atividades receptivas de turistas, a exemplo do que vinha sendo acontecendo na Europa, como forma de agregar renda as famílias (RODRIGUES, 2001).

Pode-se conceituar o turismo rural como uma atividade não agrícola inserida na pluriatividade rural, apoiando-se em Schneider (2003, p. 91), que o define como

\begin{abstract}
um fenômeno através do qual membros das famílias de agricultores que habitam no meio rural optam pelo exercício de diferentes atividades, ou mais rigorosamente, optam pelo exercício de atividades não-agrícolas, mantendo a moradia no campo e uma ligação, inclusive produtiva, com a agricultura e a vida no espaço rural.
\end{abstract}

Neste contexto, Cavaco (2011) salienta que o turismo torna-se um reconhecido vetor de diversificação do uso do espaço rural, não apenas como uma atividade econômica, mas principalmente atuando no sentido de reforçar a identidade e a imagem dos lugares, bem como a autoestima das populações locais.

Cerca de uma década mais tarde, influenciado pelas discussões sobre a sustentabilidade socioambiental catalisada no decorrer da década de 90 através da Conferência das Nações Unidas sobre o Meio Ambiente e o Desenvolvimento, a Rio-92, uma nova dimensão foi incorporada ao turismo rural, com a perspectiva do desenvolvimento da atividade pautada intrinsecamente pela promoção do segmento através da própria comunidade que reside nestes espaços. Quanto a esta característica Bartholo; Sansolo; Bursztyn (2009) destacam que

o turismo de base comunitária é compreendido como um modelo de desenvolvimento turístico, orientado pelos princípios da economia solidária, associativismo, valorização da cultura local, e, principalmente, protagonizado pelas comunidades locais, visando à apropriação por parte dessas dos benefícios advindo da atividade turística.

Neste sentido, o turismo pode ser entendido como uma atividade capaz de gerar desenvolvimento equânime para as comunidades rurais, enquanto uma prática responsável e com iniciativas de diferentes dimensões que são geridas pelos próprios moradores, maximizando assim, seus impactos positivos. Esta proposta de envolvimento comunitário no trade solidifica-se também a partir das constatações de Hall (2014) sobre a pósmodernidade, que ao mesmo tempo em que fragmentou culturas, valorizou 
àquelas que se mantiveram alheias ao processo de homogeneização, caso das comunidades rurais.

Para Cavaco (2011), estas características promovem uma vantagem competitiva do segmento, como resposta aos efeitos negativos trazidos pelo turismo de massa, pois o turismo rural de base comunitária está alicerçado no engajamento social de seus moradores, colocando-as como agentes produtivos da atividade, ao destacar que

o turismo comunitário questiona 0 mito do turismo convencional como gerador de emprego e rendimentos e denunciam as políticas centradas da atração de investimentos que não privilegiam a participação e 0 desenvolvimento múltiplo das comunidades locais, não valorizam o turismo como instrumento de redução da pobreza e de inclusão social (CAVACO, 2011, p.152).

Nesta perspectiva, considera-se também a contribuição reflexiva de Lima (2010, p. 07), quando o autor expõe que:

Pensar o Turismo de Base Comunitária, como turismo só de geração de renda é pouco. O lastro do Turismo Comunitário tem sua base na diversidade cultural e nos valores humanos. A moeda... não é recebida, é trocada! Os valores... não geram riquezas, geram nobreza!

Assim, visualiza-se que implementação de equipamentos turísticos, integrados ao meio rural valorizam o intercâmbio entre as famílias, a integração das atividades com a pesca, a agricultura familiar, a culinária local e o artesanato, criando mecanismos autônomos de valorização da memória e da identidade, que somados à hospitalidade local, podem ordenar a gestão territorial e regular a relação entre turistas e comunidades.

Para tanto, desenvolver experiências e formatar produtos turísticos de natureza rural de base comunitária exigem-se abordagens que incluem a participação direta dos atores envolvidos em sua consolidação através de uma metodologia participativa, não cabendo assim, a imposição de projetos definidos. Desta forma, o uso de ferramentas participativas na execução de etapas de desenvolvimento do segmento seja por meio de oficinas, dinâmicas ou discussões conceituais promovem a imersão da comunidade na atividade e auxilia-a no reconhecimento de seus potenciais e na ampliação da oferta turística.

Algumas destas atividades de sensibilização devem ter o objetivo de evidenciar experiências que influenciaram no processo de desenvolvimento espacial e histórico comunitário, bem como no uso de seus recursos naturais. Para tanto, alguns exemplos se destacam para esta prática, como oficinas que estimulem os moradores a desenharem um "Mapa da Comunidade", a organização de um "Calendário Histórico", a programação 
de "eventos" e a construção de equipamentos turísticos através da antiga prática solidária chamada de "Mutirão".

No caso do Mapa da comunidade, a aplicação desta ferramenta favorece a criação de uma concepção compartilhada sobre a situação atual da comunidade em relação a seus potenciais e suas limitações nos âmbitos: físico, social, ambiental e cultural (VERDEJO, 2006). Este exercício permite identificar 0 que as pessoas consideram importante em sua localidade, revelando assim, atributos que devem ser considerados no momento de inventário. Os resultados levantados por esta ferramenta, contribuem ainda para posteriormente servirem como base para a estruturação da infraestrutura local.

Neste sentido, os mapas enfatizam o planejamento de roteiros dentro da comunidade, permitido a integração entre propriedades e a socialização tanto dos benefícios quanto das técnicas locais, como o saber-fazer de artesanato e de produtos orgânicos, como doces em conserva, por exemplo, de forma a garantir um referencial cultural às peças ofertadas ao turista, indo muito além do uso do espaço por este.

Em relação ao Calendário histórico, percebe-se que esta ferramenta permite projetar os elementos singulares locais que podem ser utilizados na constituição de roteiros histórico-culturais, servindo assim como atrativo turístico e resgate da memória comum das comunidades, relevantes à consolidação do turismo rural de base comunitária. A atividade, aplicada em estudos de Cunha (2015) e Faria e Neto (2006), é relatada como de ótima receptividade pelos participantes, que de maneira geral, consideram muito gratificante a tarefa de construir o seu próprio resgate histórico.

Informações especificas das comunidades, como seu surgimento, formação, acontecimentos marcantes como visitas de pessoas famosas ou desastres naturais são alguns dos elementos que podem ser levantados para posteriormente servirem como base para o desenvolvimento de roteiros temáticos, pois se constitui em ponto de reconhecimento histórico-cultural das famílias.

Outra alternativa viável é a programação de eventos que simbolizem as características rurais da comunidade, como acontece em festas temáticas em diversas regiões do país, como datas que destacam a colheita de um cereal ou de frutas, por exemplo. Os eventos contribuem ainda para diminuir a sazonalidade ocasionada em períodos de baixa procura pela demanda do produto, geralmente em meses intermediários aos de férias escolares (BENI, 2004).

Da mesma forma, o estímulo social à prática do Mutirão, visto como uma mobilização coletiva de um grupo de pessoas para a realização de uma tarefa, evita-se que sejam socializados os custos e privatizados os benefícios ao término do planejamento da atividade. Os espaços definidos para intervenções desta natureza devem cumprir funções como de agregar produtos ou serviços de várias famílias em um mesmo lugar, como o centro receptivo turístico, onde podem ser comercializados artesanato de toda a comunidade e servir alimentação para os visitantes, para que todas as 
famílias, de forma rotativa, fiquem responsáveis por atender a demanda, por exemplo (FARIA; NETO, 2006).

O engajamento neste sentido pode ser dar de várias maneiras, onde um proprietário pode oferecer o espaço físico para a construção do equipamento ou a adaptação de uma antiga instalação, outros podem oferecer material de construção e também a mão-de-obra para a consecução dos serviços. O momento de trabalho pode ainda estreitar laços afetivos e a solidariedade através da cooperação mútua em busca de objetivos comuns.

Verifica-se, portanto, que as experiências de turismo rural de base comunitária apontam diversos benefícios econômicos, sociais e ambientais. Sendo que entre os benefícios mais frequentemente apontados, estão a diminuição do êxodo rural, por meio da geração de novas oportunidades de trabalho e renda complementar, o aumento da venda direta ao consumidor de produtos agrícolas in natura e alimentos processados e também do artesanato, promovendo assim a diversificação da economia local.

Assim, o processo de implantação do turismo percorreu desde iniciativas de Turismo Rural frustradas pela incapacidade de autogestão dos primeiros empreendedores, passando pelas iniciativas de Base Comunitária, que evidenciam as potencialidades do segmento como alternativa de desenvolvimento local e a busca pela inclusão social.

Este incremento de renda gera benefícios e melhoria das condições de vida de famílias e comunidades rurais, bem como promove o aumento da autoestima dos trabalhadores do campo, a partir da valorização de seus saberes e fazeres, além da preservação de patrimônio material e imaterial e conservação dos recursos naturais.

Ao referenciar apenas os produtos típicos locais, como é comum de se observar em eventos de turismo, se enaltece somente os objetos e não as pessoas que estão por traz desta produção. Este é o elemento norteador da base comunitária: resgatar quem produz a cultura local, pois os saberes e modos de fazer se destacam dentro da experiência proposta por este segmento ao mesmo tempo em que elevam a autoestima da população.

\section{Caracterização do objeto de estudo}

O Pinho de Baixo, possui um significativo lastro cultural que remete à questão do processo imigratório italiano. Wacelyczem (2012) aponta que, nos anos de 1860, a Itália passava por problemas econômicos, desempregos, questões sociais e os Italianos tiveram que buscar os países da Europa, devido a este cenário. Depois da Europa, passaram a se deslocarem para países dos Estados Unidos da América, Argentina e Brasil. A despeito disso, Otranto ressalta que (2012, apud Wacelyczem, p. 28, 2012), "no início do século XIX cerca de dez milhões de italianos deixaram seu país". Também Caprara (2005, apud Wacelyczem, 2012), corrobora com a questão do processo imigratório que ocorreu na Europa nesse período, enfatizando que: 
A saída dos emigrantes em busca de um país onde pudessem ter uma vida mais digna tem como fatores as transformações sociais, políticas e econômicas decorrentes da expansão do capitalismo, ou seja, os grandes problemas que encontraremos na Europa, e isto incluí a Itália.

No ano de 1875 o Brasil, segundo Caprara (2005, apud Wacelyczem, 2012), tinha como meta atrair a vinda de imigrantes com objetivo de colonizar e povoar o país. De tal modo, os imigrantes de mais de 60 países chegaram ao Brasil na busca de uma nova vida e foram se alastrando pelo território brasileiro e muitos buscaram o sul do país e a região de São Paulo. Nesta mesma linha de pensamento Bonfin, Goveia, Demczuk (2013, p. 74), apontam que: "No Brasil, entre os de 1841 e 1940 ingressaram aproximadamente 1,4 milhão de imigrantes italianos, destes, cerca de um milhão dirigiu-se para o estado de São Paulo para o trabalho nas lavouras cafeeiras, e os demais para as colônias do Sul do país".

No estado do Paraná, as mesmas autoras (2013), enfatizam que o estado recebeu uma pequena quantidade de imigrantes, aproximadamente 18 mil e fixarem-se próximos às áreas do litoral que eram habitadas e também em torno da capital de Curitiba.

Com relação ao povoamento do Pinho de Baixo localizado na área rural do município de Irati-PR, e os primeiros imigrantes Italianos foram de origem do Vêneto, região do nordeste da Itália, chegaram por volta de 1925. (WACELYCZEM, 2012). Importante destacar que estes imigrantes antes de descobrirem o Pinho de Baixo, residiram por um período no município de Campo Largo/PR, que fica aproximadamente a uma distância de $170 \mathrm{~km}$ da comunidade do Pinho de Baixo, pertencente ao município de Irati/PR. Dando continuidade a história do Pinho de Baixo com relação a imigração Italiana, Bonfin, Goveia, e Demczuk (2013, p. 74) destacam que o início da colonização, os imigrantes trabalhavam com agricultura, criavam animais, para o sustento das famílias que ali residiam no início da colonização, como também o trabalho era e é compartilhado com os filhos que "desde pequenos aprendiam e continuam aprender a lidar na terra". A partir do desenvolvimento das atividades pelos imigrantes italianos, as questões básicas foram se desenvolvendo lentamente. Exemplo disso, foi a energia elétrica que chegou no ano de 1978, através de uma usina elétrica, hoje já desativada; a água tratada chegou após 1983; no ano de 1997, foi implantada a Torre Telefônica, em 21 de dezembro de 1995 a localidade passa a se chamar Pinho de Baixo, a partir da Lei no 11.164. Anterior ao nome já mencionado, era denominado Pirabá, que segundo às autoras (2013, p. 74), o nome antigo era "em virtude da grande quantidade de pinheiros Araucárias na região".

Ainda as autoras informam (2013), que na localidade a questão da infraestrutura foi melhorando conforme os anos, mas não tanto como deveria ser. Com relação ao no de pessoas que residem no Pinho de Baixo, acerca dos dados de 2013, chegava a um número de 700 pessoas. Na questão da educação, o local conta com uma escola Municipal, onde oferta o ensino da 
pré-escola ao ensino fundamental. Nesta comunidade há uma igreja; um mercado; e um campo de futebol.

Hoje a comunidade ainda tem como a principal atividade econômica a agricultura, no entanto não deixaram a questão da preservação das tradições, costumes, os bordados e a talha. Também abarca neste conjunto de tradições da comunidade, a questão da religiosidade, a qual são devotos e celebram com fé aos Santos da comunidade "Santo Antônio, Nossa Senhora da Luz e São Sebastião, que é o Padroeiro da Comunidade". (BONFIN, GOVEIA, DEMCZUK, p. 75, 2013). Contudo, o Italian Language Guide (2005, apud Wacelyczem, 2012), destaca que:

\begin{abstract}
A maioria dos italianos são católicos romanos, cerca de $85 \%$ de toda a população. $O$ restante de toda a população apresenta uma variação quanto a sua religião, porém apresenta muçulmanos, protestantes, testemunhas de Jeová, judeus e budistas. A igreja apresenta importante influência na vida e na arte dos italianos, ou seja, a maioria das pinturas e esculturas basearam-se na religião e em contextos religiosos.
\end{abstract}

Outros costumes preservados, são as festas e uma em particular que ocorre todo o mês de fevereiro, tradição está preservada desde os primeiros imigrantes italianos que chegaram no local. A música italiana, também é preservada pela comunidade e segundo Bonfin, Goveia e Demczuk (2013, p. 76):

Os moradores reúnem-se nos finais de semana para tocar e cantar as músicas da terra natal, e através delas, expressam sua alegria e relembram suas origens. Este tipo de manifestação também está presente por meio das danças e canções típicas apresentadas em todo o estado pelo grupo de estudos da cultura italiana Chiarodiluna - que em português tem o significado de luar -, assim denominado pelo fato de o grupo apreciar a beleza da lua, especialmente quando esta se faz cheia.

Entende-se que a comunidade procura manter a cultura de seus antecedentes, através da música, arte, danças, religiosidade, formas de produção, a língua italiana e demais costumes que mantém no local.

Importante destacar que o local, além de manter as suas tradições, conta com uma série de atrativos como: vinícolas artesanais, sendo as mais visitadas Vinícolas Santo Antônio, Cosmos e Vizinoni e segundo Wacelyczem (2012, p. 30), afirma que o símbolo da imigração italiana na comunidade são as vinícolas. 
No início da imigração, o vinho era produzido em pequena quantidade, somente para o consumo das pessoas da residência, e um aspecto importante dentro desta tradição é que a bebida ainda é fabricada artesanalmente. Nos dias de hoje a produção do vinho artesanalmente chama muito atenção das pessoas, como muitas vão em busca da bebida na própria localidade, com isso tiveram que aumentar a produção, porém a demanda está sendo maior que a quantidade produzida. As vinícolas também aumentaram na região, a bebida está sendo comercializadas no próprio município.

Além da preservação das vinícolas, a comunidade conta com uma fábrica de cadeiras, que também faz parte da história da comunidade e preservação. Também a questão da gastronomia italiana, Wacelyczem (2012, p. 33), destaca que "é composta por diversos alimentos como a polenta, laticínios, massas, sopas, carne de porco, e algumas verduras, tendo uma bebida como símbolo do povo italiano, o vinho".

Dentre os itens da gastronomia, a polenta que acabou sendo uma das festas mais marcantes na comunidade. Neste aspecto Wacelyczem (2012, p. 33), corrobora com preciosas informações quanto a esta festa, que ocorre na comunidade do Pinho de Baixo desde ano de 2005, realizada no pavilhão da Igreja São Sebastião, organizada pelas famílias residentes do local. De acordo com Wacelyczem (2012, p. 36), o surgimento desta festa começou desta forma:

\begin{abstract}
O evento teve um início curioso, pois seu idealizador, o Sr. Edison, tentou incentivar o aprendizado do idioma italiano à comunidade local. No entanto, após muitas tentativas, a prática e resgate do idioma foi em vão, pois no início inúmeros moradores comparecerem às aulas dispostos a aprender, mas com o passar dos dias a demanda diminuiu a ponto de o grupo de estudos ser encerrado. Surgiu então um novo grupo de estudos, dessa vez sobre a gastronomia italiana. O número de interessados nesse aspecto da cultura foi muito maior, porém Edison acreditava que ainda faltava algo para a localidade resgatar sua identidade cultural. Propôs então aos que participavam dessas aulas de gastronomia, a realização de uma festa com alimentos oriundos da Itália, e foi então que ocorreu a primeira Festa da Polenta da localidade do Pinho de Baixo.
\end{abstract}

Além disso, o mesmo autor afirma (2012), que a construção da festa passou a ser mais um fator para preservar a questão cultural da comunidade do Pinho de Baixo, onde os residentes celebram a identidade cultural, a qual também atraem um público de aproximadamente a 600 pessoas, de acordo com a pesquisa de Wacelyczem.

Além dos fatos mencionados pelos principais autores com relação à comunidade, que o local também conta com um roteiro de cicloturismo, 
organizado pelo departamento de Turismo, do município de Irati/PR, que tem como mentor Sr. Basílio, diretor este setor.

Aliando aos fatos mencionados desde a chegada dos imigrantes no Pinho de Baixo, o local também deu iniciou as atividades do turismo no mês de março do ano de 2016 correlata ao turismo no local, com objetivo de preservar a cultura e suas tradições. Foram estabelecidas as seguintes atividades. Casa Dei Nonni, é um museu que representa a história da comunidade italiana. No interior do museu há fotos e objetos pertencentes às famílias da comunidade. Também está incluído nas atividades do turismo, café da Nonna, passeio a carroça e caminhada por uma trilha planejada no local, onde o turista pode contemplar a natureza e aprender sobre algumas espécies de árvores durante o percurso que são identificadas com os respectivos nomes científicos e populares. Além disso, Sava (2016) destaca que também há possibilidade de ofertarem mais uma atividade ligada a visita guiada às cachoeiras existentes na usina e no moinho da localidade. Segue assim, um mapa referente a localização da atividade turística principal do Pinho de Baixo (Figura 1).

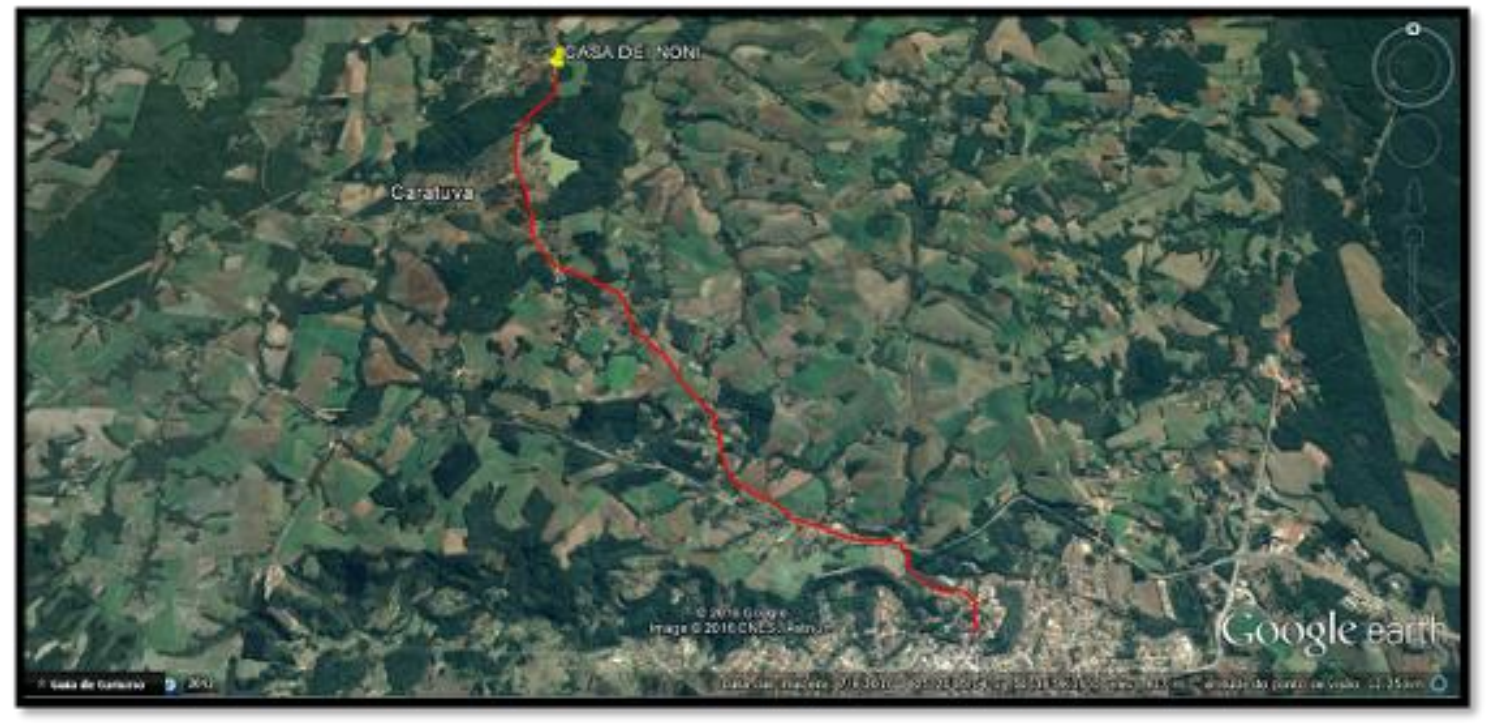

Figura 1: Localização geográfica do Pinho de Baixo em relação à Irati - PR. Figure 1: Pinho de Baixo's distance regarding from Irati - PR.

Fonte: Google Earth (2016). Source: Google Earth (2016).

A partir da fundamentação e da caracterização do objeto de estudo, o próximo tópico trata dos resultados e discussões sobre os dados encontrados em campo, visando dar inteligibilidade ao processo de planejamento e subsidiar a constituição de um estudo de campo qualitativo. 


\section{Resultados e discussões}

Como previamente demonstrado, a comunidade rural Pinho de Baixo é um produto turístico que está localizado no meio rural de Irati, recentemente inaugurado e que oferece em seu amálgama de serviços elementos que compõem o segmento do Turismo Rural de Base Comunitária. Os elementos que subsidiam tal afirmação se devem quanto sua distância física do centro urbano mais próximo, o espaço geográfico no qual está inserido e a forma como os visitantes podem utilizá-lo para seu lazer.

Para tanto, são descritos a seguir a análise do ambiente interno do destino, que correspondem respectivamente às forças (Strengths) e as fraquezas (Weaknesses) e podem ser gerenciadas para aprimoramento ou mitigação através do planejamento. Quanto ao primeiro âmbito, correlacionam-se os pontos positivos visando demonstrar a capacidade de penetração no mercado, fortalecendo assim, os esforços lançados na estruturação do produto.

A gênese desta análise se dá pela distância entre a comunidade e a região central de Irati $(P R)$, de aproximadamente $16 \mathrm{~km}$, cuja via de acesso se apropria da rodovia BR-277 (sentido Guarapuava), em trecho onde, mesmo com a rodovia com pedágio, não há cobrança deste. Após cerca de 6 quilômetros deve-se seguir por uma estrada secundária, sem pavimentação em direção ao atrativo.

Devido à localização próxima do centro urbano, o destino oferece indiretamente aos visitantes acesso rápido a hospitais, farmácias, hotéis, entre outros empreendimentos necessários, seja por motivos emergenciais ou de apoio. Além desta vantagem, os moradores de Irati e de cidades adjacentes como Fernandes Pinheiro, Teixeira Soares e Rebouças são diretamente beneficiados com a ampliação de espaços de lazer e descanso mesmo em pequenos intervalos de tempo livre, como em finais de semana.

Os demais elementos positivos identificados remetem-se aos serviços oferecidos pela comunidade. Do ponto de vista de infraestrutura física, destaca-se o Museu Casa dei Nonni, que se trata de uma casa construída em madeira e que possui uma identidade simbólica sobre a cultura Italiana uma vez que foi doada por uma família de imigrantes deste país e posteriormente transferida à comunidade em questão, que dimensionou seu uso para um museu que retrata elementos culturais (Figura 2).

Além de abrigar as peças, o elemento identitário contido no Museu não foi unicamente transferido e adaptado para um outro espaço que visou apropriar-se de algo híbrido. Cabe ressaltar que a comunidade Pinho de Baixo é povoada por imigrantes italianos que optaram por residir neste espaço e que imputem suas raízes nas formas de trabalho, convívio social e gastronomia. 


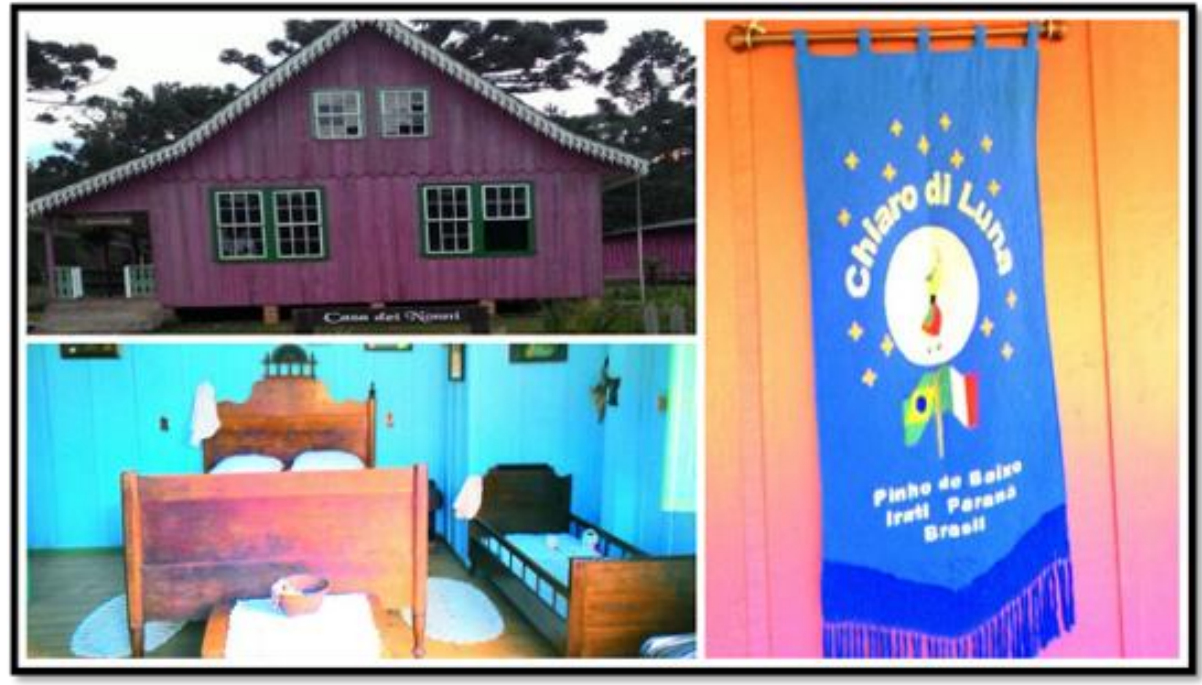

Figura 2: Museu Casa dei Nonni.

Figure 2: Casa dei Nonni museum.

Fonte: Os autores (2016). Source: The authors (2016)

No decorrer da visita, há um processo de educação e interpretação sobre os objetos em amostra, realizado pelo idealizador do projeto. Esta visita guiada torna os elementos característicos menos intangíveis para àqueles que os apreciam, tocando por vezes, os sentimentos e o simbolismo das peças se transvestem em atrativos. A disposição do acervo é compatível com o espaço edificado, não poluindo visualmente a casa e permitindo a compreensão do tema proposto. Destaca-se, por fim, que os valores elencados em Lima (2010) se fundamentam sob este panorama apresentado.

Ainda em relação ao Museu, produtos artesanais como bolachas e doces caseiros, mel coletado na comunidade, vinho produzido de forma extensiva e bordados em panos de prato são comercializados, visando agregar renda e promover souvenirs para os visitantes. A importância deste contexto reside na caracterização do turismo de base comunitária, como já destacado pelos conceitos fundantes deste estudo (CAVACO, 2011).

Sobre a infraestrutura básica do local, são observadas as áreas delimitadas para o uso público, que definem as atividades atualmente disponibilizadas. Há bancos com características rústicas, cercas que não agridem paisagísticamente a estética do lugar, passeios em carroças e também por trilhas em meio às áreas conservadas. Portanto, como indica Dias (2003) à análise dos empreendedores consistiu na identificação das alternativas possíveis para 0 desenvolvimento do segmento, comprometendo assim, em menor âmbito o ambiente natural

Quanto ao passeio que utiliza os equinos, observa-se um trapiche (Figura 3) que auxilia os visitantes ao acesso à carroça, como um elemento inovador em destinações que utilizam esta prática, facilitando sua utilização por crianças e idosos, por exemplo. 


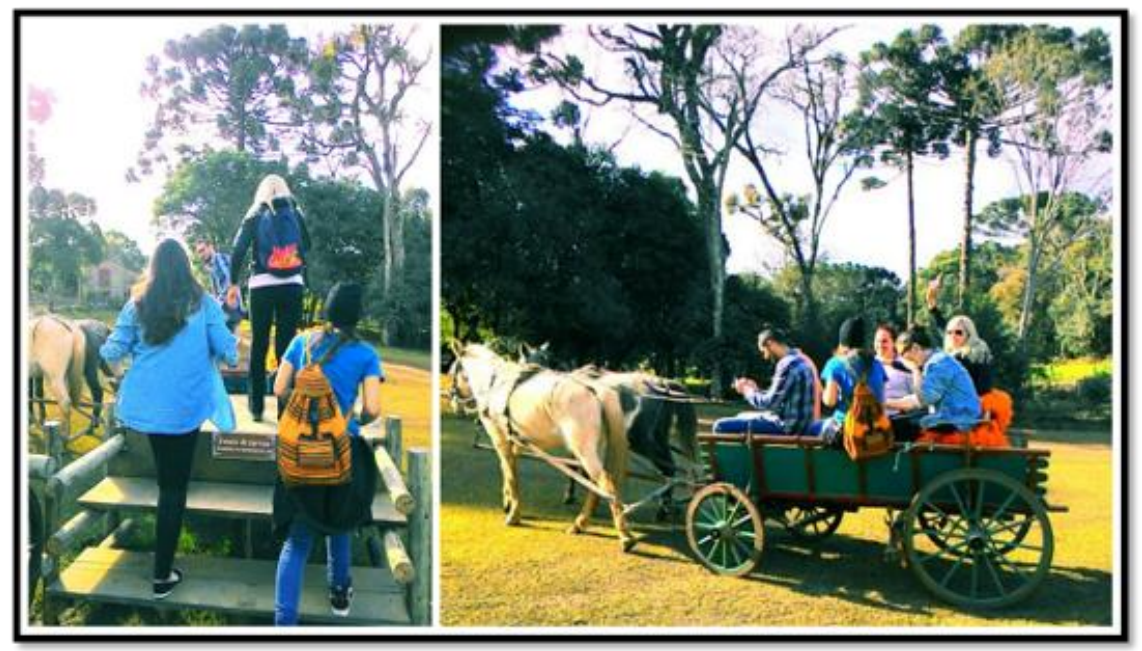

Figura 3: Trapiche e passeio de carroça pela propriedade

Figure 3: Deck and cart ride around the property

Fonte: Os autores (2016). Source: The Authors (2016).

Por fim, configuram-se como duas forças o café caboclo que é oferecido ao custo de $R \$ 18,00$ como um elemento complementar da oferta e a Associação de Turismo Rural de Pinho de Baixo, cujos membros são responsáveis pela confecção do mesmo. O cardápio é variado, opções de tortas, pães, queijo, mel, café, chá e leite.

A diversidade de alimentos não se afirma enquanto diferencial competitivo, mas sua forma de produção sim, uma vez que a renda gerada com este serviço é distribuída entre diversas famílias, evitando assim a monopolização dos benefícios do turismo, conforme orientado por Bartholo, Sansolo e Bursztyn (2009) pelo princípio de economia solidária e associativismo.

Para completar a análise sobre o ambiente interno, também são citados e discutidos os pontos negativos (fraquezas) que as práticas em campo ilustraram durante o mês de abril do corrente ano. Esta caracterização inicia-se igualmente pelo atributo acesso, já anteposto como uma força. O revestimento analítico neste momento trata da questão de orientação de sinais que auxiliem o visitante chegar no produto turístico.

Não há, tanto na rodovia BR 277 quanto na estrada rural placas de sinalização que indiquem o atrativo, sua distância ou direções a serem tomadas para seu alcance. Como este estudo tem caráter compreensivo e não explicativo, ainda não existem técnicas de coleta de dados primários com os membros da Associação de Turismo local, portanto, apenas pode-se supor que maiores preocupações foram lançadas na estruturação do espaço, que muito recentemente está aberto ao uso, e que a partir deste momento, outros esforços estão sendo planejados.

A falta de sinalização inibe ainda a promoção do produto para pessoas que estão viajando pela região, mas que não necessariamente entram nos municípios em busca de informações ou sugestões de passeios. 
Portanto, é um elemento que deve ser brevemente sanado sob a perspectiva de colocar em risco o futuro do empreendimento.

Quanto à trilha presente no atrativo, há pouco material interpretativo, limitando-se a placas que identificam o nome científico de algumas árvores (Figura 4a) e à condução personalizada no seu trajeto por um morador local. A trilha precisa ser reestruturada, sobretudo em lugares que devem ser áreas de restrição, programas de educação e interpretação ambiental e planejamento de solo (Figura 4b), uma vez que, aumentada a demanda na propriedade, impactos serão sentidos em curto ou médio prazo, podendo comprometer assim, a viabilidade desta atividade.

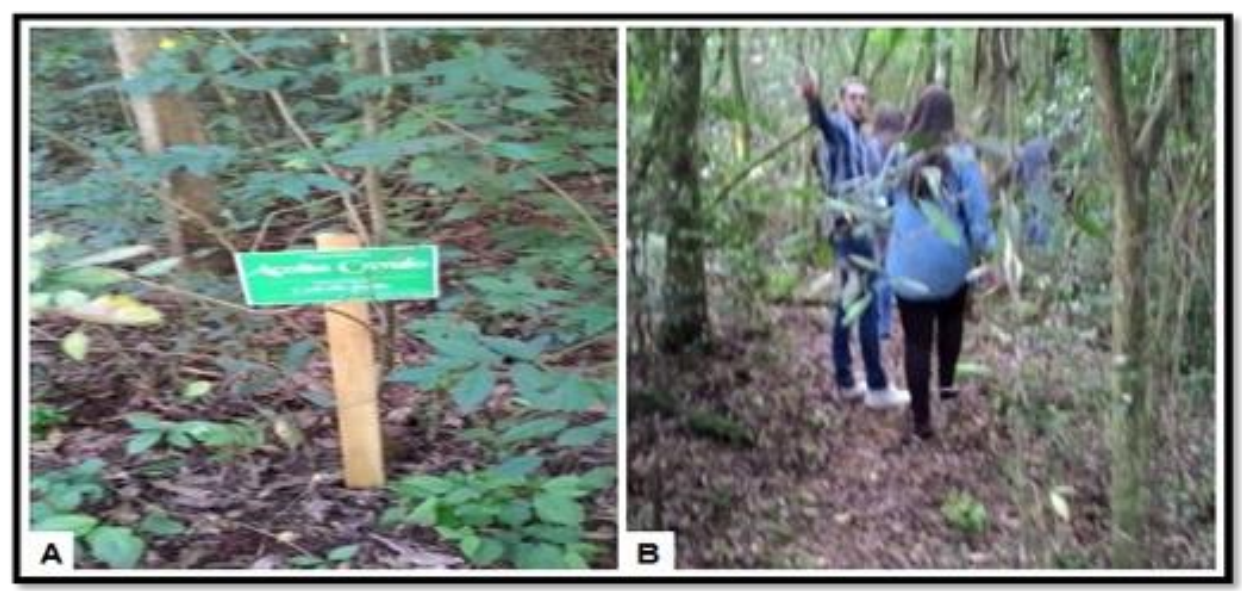

Figura 4: Placa informativa (a) e característica do solo na trilha (b).

Figure 4: Information board (a) and soil detail on track (b).

Fonte: Os autores (2016). Source: The Authors (2016).

No que tange à comercialização das atividades, todos os ticket's são vendidos no interior do Museu, tornando-o também um ponto de venda. A utilização deste espaço deveria restringir-se à valorização do acervo e da memória, portanto, a edificação de um local específico é recomendada para tal prática. Sugere-se que um centro de visitantes contemple todo o âmbito financeiro, ou como ação a curto prazo, elaborar comandas de serviços onde os visitantes no momento de término do passeio a liquidem de uma única vez.

Por fim, em alguns pontos do atrativo são visualizadas carcaças de animais desprezadas em meio à natureza. Além do potencial de contaminação de solo e cursos de água, a matéria orgânica atrai insetos, espécies de aves e em menor grau, carnívoros em busca de alimentos, podendo comprometer a segurança dos visitantes e também na poluição visual da paisagem, uma vez que estes não possuem nenhuma conotação com a cultura rural abordada pelo condutor no decorrer do passeio.

Encerra-se desta forma, a caracterização e avaliação dos pontos fortes e fracos do ambiente interno da propriedade, bem como de suas reflexões e cruzamento com a base teórica fundante. Visando complementar a matriz avaliativa, a análise do ambiente externo é desenvolvida, abordando as oportunidades e ameaças ao produto em estudo. 
Quanto às oportunidades, esta região do município recebe anualmente uma das edições do evento Cicloturismo Irati, chamada de etapa Pinho de Baixo. Neste, os ciclistas pedalam pelas estradas do local, e fazem uma parada para alimentação e descanso, antes de completar o percurso. Ações intra-setoriais como agregar a vinculação da marca da comunidade na divulgação do evento é uma oportunidade que permite dinamizar o reconhecimento do atrativo.

$\mathrm{Na}$ mesma esteira de aproveitar o gradual aumento no interesse sobre áreas não urbanas (CAVACO, 2011), sugere-se a implantação de um circuito turístico entre Pinho de Baixo e a comunidade rural Itapará, no mesmo município. Atividades de interesse comum, como trekking e cavalgadas entre as duas localidades, podem estimular o desenvolvimento sustentável e ampliar os benefícios do turismo.

Por fim, a criação de um "selo local" que garanta a procedência de gêneros alimentícios ou de peças de artesanato produzidos na região permitem a identificação ou rastreamento dos mesmos e agrega valor ao visitante por reconhecer que os lucros desta compra serão destinados à comunidade que o produziu, capaz de melhorar a qualidade de vida dos moradores.

O último aspecto da análise recorre aos elementos que podem comprometer o ciclo de vida do produto, consideradas como ameaças (Threats) e que não há possibilidade de intervenção direta dos empreendedores para saná-las.

Assim, mais uma vez recorre-se às vias de acesso (Figura 5). Os aproximados 10 quilômetros em estrada não pavimentada possuem uma volátil qualidade de deslocamento, uma vez que as chuvas e o trânsito de veículos alteram a situação da mesma em intervalos curtos de tempo. Da mesma forma, a experiência do visitante pode ser comprometida se este tiver dificuldades de acesso ou porventura tenha problemas mecânicos em seus veículos.

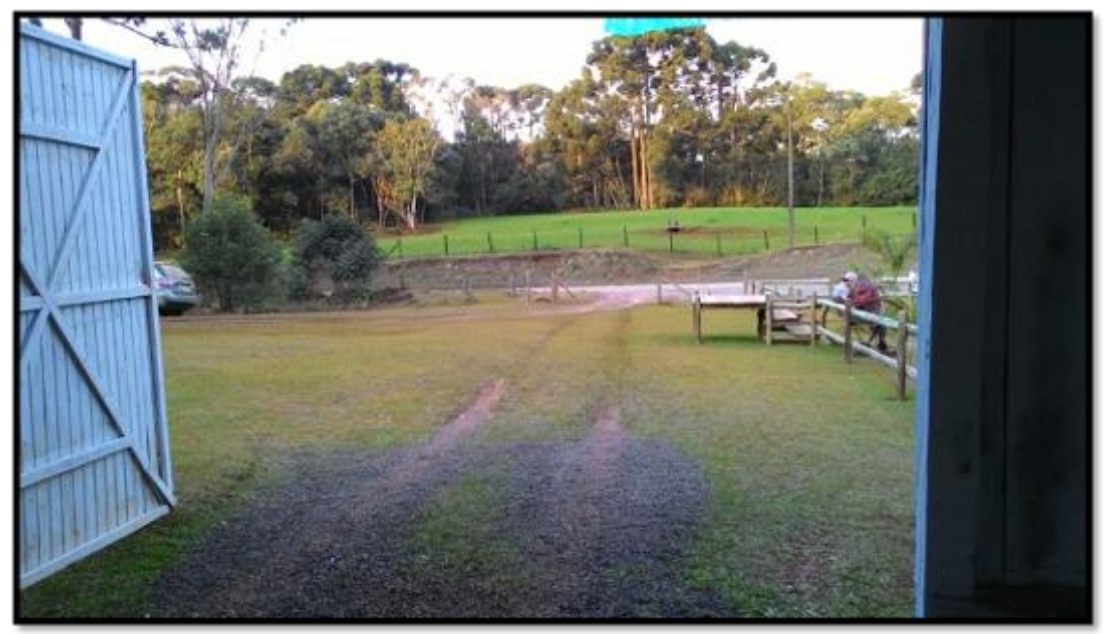

Figura 5: Paisagem que demonstra a via de acesso ao empreendimento.

Figure 5: Landscape that shows the access road to the project.

Fonte: Os autores (2016). Source: The Authors (2016). 
Em uma escala maior, há uma efetiva necessidade de divulgar o produto para mercados locais e regionais, por meio de diferentes estratégias. Notas em jornais impressos e em programas de rádio, redes sociais, placas publicitárias (outdoors ou billboards) a nível local podem servir como instrumentos de promoção efetivas. Contudo, pontos de vendas como agências de viagens e turismo (Irati possui duas) também são estimuladas em uma abrangência que extrapole os limites territoriais do município, como em mercados de Ponta Grossa, Prudentópolis e Curitiba. Também são sugeridas a participação em eventos específicos para a atividade, parcerias com universidades, hotéis, restaurantes e empresas de transporte, para atingir este objetivo.

A terceira ameaça considera a entrada de concorrentes no mesmo segmento de turismo rural. Considerando que a localidade Pinho de Baixo está localizada em uma região onde municípios adjacentes também possuem características rurais, a estruturação de concorrentes deve ser avaliada. Contudo, os diferencias deste local se configuram na cultura italiana, que deve ser enfatizada aquém de atividades de cunho eminentemente rural.

Conclui-se desta forma, a análise dos ambientes interno e externo do produto recém-inaugurado em Irati, com ênfase na sua caracterização e análise primária do espaço, com base em conceitos do turismo rural de base comunitária. Retifica-se a importância do mesmo para a ampliação da oferta turística municipal, como atividade capaz de gerar desenvolvimento e preservar identidades culturais.

Visando sintetizar os resultados encontrados com a análise SWOT o Quadro 1 resume os dados previamente detalhados.

Quadro 1: Síntese da matriz SWOT.

Frame 1: SWOT matrix shynthesis.

\begin{tabular}{|l|l|}
\hline \multicolumn{1}{|c|}{ Pontos Fortes } & \multicolumn{1}{c|}{ Pontos Fracos } \\
\hline Atrativo próximo ao centro de Irati & Inexistência de sinalização \\
\hline Singularidade cultural local & $\begin{array}{l}\text { Trilhas sem elementos interpretativos } \\
\text { autoguiados }\end{array}$ \\
\hline Interpretação personalizada do acervo & Falta de planejamento para atividades livres \\
\hline Comercialização de produtos artesanais & $\begin{array}{l}\text { Carcaças de animais que atraem insetos e } \\
\text { podem transmitir doenças }\end{array}$ \\
\hline $\begin{array}{l}\text { Infraestrutura em harmonia com o meio } \\
\text { ambiente }\end{array}$ & $\begin{array}{l}\text { Venda de tickets de atividades em } \\
\text { impróprio }\end{array}$ \\
\hline Formação de uma Associação local & Comprometimento da sustentabilidade \\
\hline \multicolumn{1}{|c|}{ Ameaças } \\
\hline $\begin{array}{l}\text { Implantar um selo local dos produtos } \\
\text { Aproveitar a edição local do evento } \\
\text { cicloturismo para agregar valor ao atrativo }\end{array}$ & $\begin{array}{l}\text { Inexistência de divulgação do atrativo por } \\
\text { agências, universidades e hotéis }\end{array}$ \\
\hline Desenvolver um circuito turístico rural & Entrada de novos concorrentes \\
\hline
\end{tabular}

Fonte: Os autores (2016). Source: The Authors (2016).

Verifica-se por fim, que existem mais elementos a serem aproveitados e sanados no ambiente interno do empreendimento, possibilitando assim ações potencializadoras e corretivas visando garantir a consolidação do 
produto enquanto uma nova opção para o segmento de turismo rural. Considera-se ainda, que mesmo em menor quantitativo, as implicações qualitativas que 0 ambiente externo demonstrou necessitam de planejamento e engajamento, seja comercial ou político para a manutenção e possibilidade de crescimento do atrativo.

\section{Considerações finais}

O turismo rural caracteriza-se como uma alternativa de desenvolvimento de um local, abrangendo a esfera econômica, cultural, social e ambiental permitindo assim a geração de empregos, resgate histórico, preservação de patrimônios e da natureza.

$\mathrm{Na}$ comunidade de Pinho de Baixo o turismo rural foi o segmento escolhido para desenvolver o local e na tentativa deste promover a cultura local. Conforme o apresentado nos resultados desta pesquisa, elementos elencados na matriz SWOT devem agir conjuntamente para se concretizar a implantação da atividade.

Observou-se que existe em geral por parte dos associados a vontade de manterem o empreendimento e abrirem novas oportunidades de crescimento. Características como as paisagens formadas por matas, as trilhas disponíveis, passeios a cavalos e os produtos artesanais já se encontram em uso, contudo carecem de melhorias.

Neste sentido, partindo do pressuposto do turismo rural de base comunitária, baseou-se no processo de planejamento turístico para compreender o estágio de criação e desenvolvimento do empreendimento.

O objetivo de identificar os possíveis recursos naturais/culturais que possam vir a se tornar atrativos turísticos foi alcançado pela pesquisa observante em campo e posterior cruzamento com o embasamento apresentado em tópico próprio. O segundo momento visou analisar qualitativamente as informações coletadas. Identificou-se assim, que todas as atividades se enquadram no contexto do turismo rural de base comunitária.

Assim, o empreendimento pode constituir um novo atrativo no município de Irati, com potencial a desenvolver para que seus pontos fracos e as ameaças não comprometam a existência do atrativo nos anos subsequentes.

\section{Referências}

ALMEIDA, J.A; FROEHLICH, J.M; RIEDL,M (orgs). Turismo Rural e Desenvolvimento Sustentável. Campinas, SP, Papirus, 2000.

BARRETTO, M; TAMANINI, E. Redescobrindo a ecologia no turismo. Caxias do Sul, RS: EDUCS, 2002.

BARTHOLO, R.; SANSOLO, D. G; BURSZTYN, I. (Orgs.). Turismo de base comunitária: diversidade de olhares e experiências brasileiras. Rio de Janeiro: Letra e Imagem, 2009. 
BENI, M. C. Análise Estrutural do Turismo, São Paulo: Senac, 2004.

BONFIM, A. C. C; GOVEIA, E. F; DEMCZUK, P G. Estudo sobre a Implantação de uma Cantina Italiana na Comunidade do Pinho de Baixo, Irati-PR: Uma proposta para o Desenvolvimento Turístico da Localidade. In: LADWIG, N. I; COSTA, R. S. (Orgs.). Debates Interdisciplinares. Palhoça: Ed. Unisul, 2013, pp. 71 a 88.

BRASIL, Ministério do Turismo. Diretrizes para o Desenvolvimento do Turismo Rural no Brasil. 2004. Disponível em: http://www.turismo.gov.br/ sites/default/turismo/o ministerio/publicacoes/downloads publicacoes/Diretri zes Desenvolvimento Turismo Rural.pdf. Acesso em 29/08/2016.

CAVACO, C. Turismo Rural Comunitário (TRC) e Desenvolvimento Local na América Latina - Um olhar Europeu. In: SOUZA, M.; ELESBÃO, I. (org.) Turismo Rural: Iniciativas e inovações. Porto Alegre: Ed. UFRGS, 2011.

CEZÁRIO, J.H.A. Avaliar a adequação da propriedade Recanto Daneliv à atividade turística no meio rural (Trabalho de Conclusão de Curso, Curso de Turismo, Universidade Estadual do Centro Oeste - UNICENTRO, 2014).

CUNHA, A.M. Turismo rural de base comunitária: a experiência de Santo Antônio da Patrulha (RS). Revista Brasileira de Ecoturismo, São Paulo, v.7, n.4, nov2014-jan2015, pp.750-761.

DIAS, R. Planejamento do Turismo: Política e desenvolvimento do turismo no Brasil. São Paulo: Atlas, 2003.

DREHER, M.T. Planejamento do turismo em áreas não urbanas: envolvendo a comunidade. In: Congresso Internacional sobre Turismo Rural e desenvolvimento sustentável, 2003, Joinville. Anais. As políticas públicas e ações privadas no turismo rural. Joinville, IELUSC, 2004. P. 241- 249. Disponível em: http://www.ufrgs.br/pgdr/arquivos/623.pdf. Acesso em 29/08/2016.

FARIA, A.A.C; NETO, P.S.F. Ferramentas de diálogo: qualificando o uso de técnicas de DRP, Brasília, MMA, 2006.

HALL, S. A identidade cultural na pós-modernidade. Rio de Janeiro: Editora Lamparina, 2014.

LIMA, F.A.S. Turismo Comunitário: uma história pra contar. In. BRASIL. Dinâmica e diversidade do turismo de base comunitária: desafio para a formulação de política pública. Brasília: Ministério do Turismo, p.07-08, 2010.

MIELKE, E.J.C; NASCIMENTO, D. Desarrollo Turístico Regional: el diagnóstico estratégico participativo ponderado - DEPP, aplicaciones y retos a laplanificación turística. Anais do VI Seminário da Associação Brasileira de Pesquisa e Pós-Graduação em Turismo, São Paulo, SP, 2009, 10-11.

PETROCHI, M. Turismo Planejamento e Gestão. São Paulo, Futura, 1998. RODRIGUES, A.B. Turismo Rural: Práticas e perspectivas. São Paulo: Contexto, 2001.

SAVA, P.H. Pinho de Baixo passa a contar com museu da comunidade. Irati/PR, 15 de março de 2016. Disponível em: http://radionajua.com.br/ 
noticia/noticias/irati-e-regiao/pinho-de-baixo-passa-a-contar-com-museu-dacomunidade/33639. Acesso em 29/08/2016.

SCHNEIDER, S. A pluriatividade na agricultura familiar. Porto Alegre: Editora da UFRGS, 2003.

VERDEJO, M. E. Diagnóstico Rural Participativo: Guia prático DRP. Brasília: MDA/Secretaria da Agricultura Familiar, 2006.

Leandro Baptista: Universidade Estadual do Centro-Oeste, Irati, PR, Brasil.

E-mail: leandro.baptista@live.com

Link para o currículo Lattes: http://lattes.cnpq.br/4353198473576287

Elieti Fátima de Goveia: Universidade Estadual do Centro-Oeste, Irati, PR, Brasil.

E-mail: elietigoveia27@hotmail.com

Link para o currículo Lattes: http://lattes.cnpq.br/4636495649124472

Data de submissão: 02 de novembro de 2016

Data de recebimento de correções: 17 de dezembro de 2018

Data do aceite: 17 de dezembro de 2018

Avaliado anonimamente 